\title{
The Influence of Emotional Labor on Burnout: Centered on the Stress Coping Strategy and Moderating Effect of Social Support
}

\author{
Yeong-Gyeong Choi and Kyoung-Seok Kim
}

\begin{abstract}
Today many company are aware of the importance of emotional labor and they try to create profit through emotional labor. Those who perform emotional labor have low job satisfaction, burnout and give negative influence on their organizations. Therefore, this study set stress coping strategy and social support as moderating variables, grasped what influences emotional labor had on burnout, and grasped whether the stress coping strategy and social support eased the influence on the burnout.
\end{abstract}

Index Terms - Emotion labor, burnout, stress coping strategy, social support.

\section{INTRODUCTION}

Due to development of economic society, the proportion of service industry in the whole businesses is increasing, and service quality is getting more important. Service industry employees are being required by organizations to hide their emotions and express those desired by customers, and they have to express emotions prescribed by organizations when they encounter customers by controlling their emotions. This stress is called emotional labor(Hochschild, 1983) [1]. Job satisfaction of employees who perform emotional labor is low, and their organizational commitment is deteriorated. Emotional labor harms psychological peace and has negative effects on job satisfaction and organizational commitment.

Burnout may occur to these service industry employees, and it is a result of continuous and repetitive emotional pressure that takes place while they maintain close relationships with people for long. The reason why the concept of burnout has come to be considered important is that burnout causes both organizational members and an organization itself to have adverse effects. The need that a wide range of organizational groups including service and general companies should understand lots of factors and conditions that result in burnout is being emphasized. Besides, even if emotional labor occurs in equal work environments, its influences on burnout appear differently.

Therefore, identifying variables that moderate negative effects of emotional labor is also a meaningful research subject. Thus, this study tries, based on preceding researches, to learn stress coping strategies that relieve negative effects of emotional labor on burnout and examine moderating variables of social support.

The purpose of this study is as follows. First, grasp if

Manuscript received April 6, 2014; revised June 18, 2014.

The authors are with the Kyungpook National University, Business Administration (e-mail: regulusmw@hanmail.net). emotional labor would influence burnout. Second, grasp if stress coping strategies would be able to relieve the influence on burnout. Third, grasp if social support would be able to relieve the influence on burnout.

\section{MAIN BODY}

\section{A. Emotional Labor}

Emotional labor was a term first coined by Hochschild. She defined emotional labor as "the management of feeling to create a publicly observable facial and bodily display, emotional labor is sold for a wage and therefore has exchange value"(Hochschild, 1983) [1]. Hochschild describes two types of emotional acting: surface acting and deep acting. Surface acting involves employees simulating emotions that are not actually felt, by changing their outward appearances(i.e, facial expression, voice tone, or gestures) when exhibiting required emotions. Deep acting occurs when employees' feeling do not fit the situation, they use their past experience or training to work up appropriate emotions.

Ashforth \& Humphrey defined emotional labor as "the act of displaying appropriate emotions"(Ashforth \& Humphrey, 1993) [2]. Morris \& Feldman defined emotional labor as "the effort, planning, and control needed to express organizationally desired emotion during interpersonal transactions"(Morris \& Feldman, 1996) [3]. Grandey(2000) defined emotional labor as "the process of regulating both feelings and expressions for organizational goals" [4].

It was found that typical researches have not clearly agreed on the conceptual definition of emotional labor, and there have arisen conceptual differences due to a matter of perspective. The point that preceding researches commonly claim is that emotional labor occurs in organizations where employees have to hide their individual emotions and express those required by organizations.

Thus, this study defines emotional labor as efforts of employees to control their individual emotions and expressions in order to express those required by organizations.

In addition, examining preceding researches dealing with emotional labor dimensions, since Hochschild first suggested surface acting and deep acting, emotional labor dimensions have not been clearly determined until today. Although plenty of researches on emotional labor dimensions are presently being conducted, no agreement has been brought about yet. Many of researches have dealt with emotional labor dimensions by using surface acting and deep acting that only focus on emotional expressions, and the results are also 
limited. Thus, this research, to approach emotional labor multi-dimensionally, composed emotional labor dimensions with surface acting, deep acting, frequency, strength, and diversity.

\section{B. Burnout}

Maslach(1993) defined burnout as an overall phenomenon that organizational members who frequently make interpersonal relations experience, and a sequential intensive course [5]. Emotional exhaustion is a sort of role-related stress, and individuals who experience it come to lose interest in and passion for everything, and feel fatigue and a sense of loss due to loss of work motivation or loss of interest. Depersonalization represents that individuals get psychologically derived from customers, colleagues, works, and organizations, and have sardonic and callous attitudes towards them. Employees who experience depersonalization often treat people like things or perceive that they are irrelevant. Reduced personal accomplishment means that employees negatively react to their jobs due to deterioration of desire for job achievement and reduction of will to succeed in works. Moreover, it makes them invest little time and energy in customers, which leads to lack of accomplishment, so that they assess their abilities negatively.

\section{Stress Coping Strategies}

Employees experience situations that arouse stress while working. Even if they are exposed to stress factors, the influence may vary with how they cope. The effect of stress on individuals varies not only with the absolute level of stress, but with ways to perceive stress and the degree that they get helps or cope rationally to reduce stress. When employees face stressful situations or threatening conditions that they think they cannot bear with resources they have, they consciously and unconsciously tend to increase their resources or try to relieve tension to reduce internal and external demands, and these acts to react, adjust, and respond to stress is called coping.

\section{Social Support}

Social support, as a byproduct generated from constant interrelationship among people, is a concept that means emotional solidarity to trust and help one another, functions to help react and adjust in stressful situations, reduces the possibility of occurrences of undesirable stress in daily life, and contributes to psychological peace.

Cohen \& Hoberman (1983) defined social support as a positive resource that an individual can gain from interpersonal relations, and House (1981) defined it as a function that helps solve problems by relieving the severity, and protects individuals from harmful effects of stress and promotes healthy behaviors by making them less sensitive to stress.

\section{RESEARCH Models AND RESEARCH MethodS}

\section{A. Research Models and Hypothesis Setting up}

This study, to learn the effect of emotional labor on burnout, set emotional labor as an independent variable and burnout as a dependent variable. In addition, in order to learn the effects of stress coping strategies and social support, moderating variables, on emotional labor and burnout, research models as below were developed.

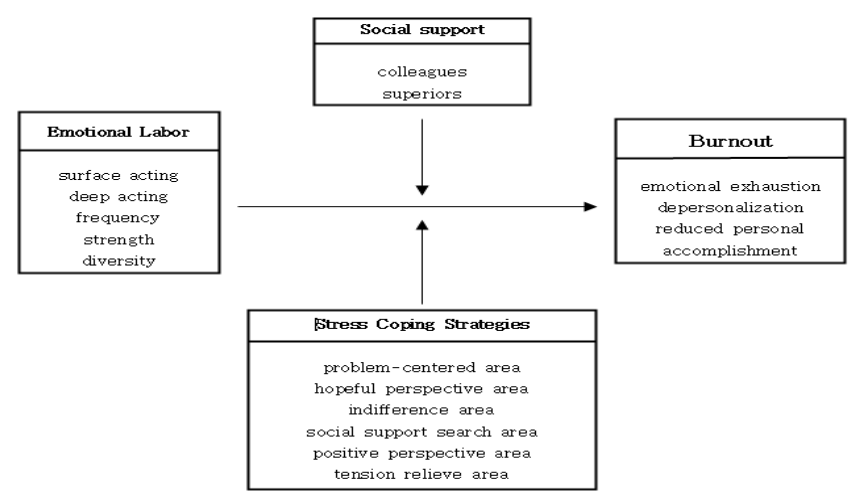

Fig. 1. Research model.

H1: Emotional labor will have a positive $(+)$ effect on burnout.

H1-1: Emotional labor will have a positive (+) effect on emotional exhaustion.

H1-2: Emotional labor will have a positive (+) effect on depersonalization.

H1-3: Emotional labor will have a positive (+) effect on reduced personal accomplishment.

$\mathrm{H} 2$ : Stress coping strategies will moderate the relationship between emotional labor and burnout.

H2-1: Stress coping strategies will moderate the relationship between emotional labor and emotional exhaustion.

H2-2: Stress coping strategies will moderate the relationship between emotional labor and depersonalization.

H2-3: Stress coping strategies will moderate the relationship between emotional labor and reduced personal accomplishment.

H3: Social support will moderate the relationship between emotional labor and burnout.

H3-1: Colleagues of social support will moderate the relationship between emotional labor and emotional exhaustion.

H3-2: Colleagues of social support will moderate the relationship between emotional labor and depersonalization.

H3-3: Colleagues of social support will moderate the relationship between emotional labor and reduced personal accomplishment.

H3-4: Superiors of social support will moderate the relationship between emotional labor and emotional exhaustion.

H3-5: Superiors of social support will moderate the relationship between emotional labor and depersonalization.

H3-6: Superiors of social support will moderate the relationship between emotional labor and reduced personal accomplishment.

\section{B. Operational Definition and Measurement of Variables}

Emotional labor was defined as efforts of employees to control their individual emotions and expressions in order to express those required by organizations. Brotheridge \& Lee's research (1998) was used after being modified and 
complemented, and totally 23 items were constructed. Measurement of variables was conducted focusing on diversity, strength, frequency, surface acting, and deep acting. Each item was measured with Likert's five-point scale.

Burnout was defined as a reaction to chronic stress accumulated through interpersonal relations, and a state that deteriorates organizational performance due to physical and emotional exhaustion, and MBI scale developed by Maslach \& Jackson (1981) was used after being modified and complemented. Each item was measured with Likert's five-point scale.

Social support was defined as helping employees conduct their duties or change stress factors related to the duties. The questionnaire was composed of totally 24 items, and the type of social support consisted of four sub-variables, that is, seven items for emotional support, five items for appraisal support, six items for informative support, and six items for physical (instrumental) support. Each item was measured with Likert's five-point scale.

Coping was defined as efforts of individuals to overcome, tolerate, reduce, and minimize environmental and internal demands and conflicts being burdens to them. A tool developed by Lazarus \& Folkman (1984) was used after being modified and complemented, reduced to 33 items. It consisted of eight items for problem-centered area, five items for hopeful perspective area, six items for indifference area, seven items for social support search area, four items for positive perspective area, and three items for tension relieve area. Each item was measured with Likert's four-point scale.

\section{AnAlysis Results AND Hypothesis Testing}

\section{A. Research Subjects}

This study selected employees engaged in service organizations of hotels and department stores, performing emotional labor, as research subjects. The employees were working at five-star hotels and department stores located in Daegu, Korea. Totally 400 questionnaires were distributed and 365 were returned, and 333 were used for analyses excluding 32 questionnaires that contained negligent responses.

\section{B. Validity and Reliability Analyses}

In order to maintain minimum content validity that measurement tools should equip to measure concepts or attributes precisely, it was made based on questionnaire items whose validity had already been verified in typical researches. And in order to evaluate construct validity that represents what the measurement tools used by researchers actually measured and how appropriately the abstract concepts that researchers intended to measure were measured, the Factor Analysis was conducted. For the Factor Analysis, of many methods being generally used, the Principle Component Analysis being the most widely used was used, and construct validity was analyzed by applying the Varimax Rotation.

\section{Data Analysis}

The data collected for this study was analyzed by using SPSS(Statistical Package for the Social Science) WIN 17.0. For analysis techniques, frequency and percentage were calculated to grasp demographic characteristics of the subjects, the Factor Analysis was conducted by using the Varimax Rotation to select valid items, and Cronbach's alpha coefficients were calculated to verify validity of the measurement tools. An average and standard deviation of the measuring variables were calculated, and in order to learn correlations among the variables, the Pearson's Correlation Analysis was conducted. And the Hierarchic Regression Analysis was conducted to learn the effect of emotional labor on burnout, and the Hierarchic Moderated Regression Analysis was conducted to examine, on the relationship between emotional labor and burnout, the moderating effects of stress coping and social supports of superiors and colleagues.

\section{TEST OF HyPOTHESES}

\section{A. The Impact of Emotional Labor on Burnout}

TABLE I: TEST ON THE IMPACT OF EMOTIONAL LABOR ON BURNOUT

\begin{tabular}{|c|c|c|c|c|c|c|c|}
\hline & & \multicolumn{2}{|c|}{ emotional exhaustion } & \multicolumn{2}{|c|}{ depersonalization } & \multicolumn{2}{|c|}{ reduced personal accomplishment } \\
\hline & & 1 & 2 & 1 & 2 & 1 & 2 \\
\hline & & Beta & Beta & Beta & Beta & Beta & Beta \\
\hline \multirow{4}{*}{$\begin{array}{l}\text { demographic } \\
\text { variables }\end{array}$} & gender & .100 & .054 & .087 & .066 & -.039 & -.012 \\
\hline & school career & $.184 * *$ & -.005 & .037 & -.028 & -.126 & -.029 \\
\hline & age & -.012 & $.131 *$ & .047 & .085 & .121 & .083 \\
\hline & job position & -.079 & -.097 & -.083 & -.086 & .024 & .026 \\
\hline \multirow{5}{*}{$\begin{array}{l}\text { independent } \\
\text { variable }\end{array}$} & diversity & & .063 & & .053 & & -.011 \\
\hline & strength & & -.072 & & .065 & & -.035 \\
\hline & frequency & & $.407 * * *$ & & $208 * *$ & & $-.305 * * *$ \\
\hline & surface acting & & $.278 * * *$ & & .104 & & -.055 \\
\hline & deep acting & & $-.097 *$ & & -.007 & & $.157 * *$ \\
\hline$R^{2}$ & & .052 & .438 & .012 & .099 & .038 & 145 \\
\hline$R^{2} \Delta$ & & & .386 & & .086 & & .107 \\
\hline$F$ & & $4.491 * *$ & $27.985 * * *$ & 1.016 & $3.923 * * *$ & $3.264 *$ & $6.079 * * *$ \\
\hline$p$ & & .002 & .000 & .399 & .000 & .012 & .000 \\
\hline
\end{tabular}

In order to learn the impact of emotional labor on burnout, a hierarchical regression analysis was done by having the 
demographic variables such as gender, school career, age and job position as controlled variables, emotional labor as independent variable and burnout as dependent variable. The results are as following.

School career $(\beta=0.184, p<0.01)$ was found to have impact on emotional exhaustion. An organization member with higher school career had higher emotional exhaustion. Frequency $(\beta=0.407, p<0.001)$, surface acting $(\beta=0.278$, $p<0.001)$ and deep acting $(\beta=-0.097, p<0.05)$ were found to have impact on emotional exhaustion. When the frequency of emotional labor increases or where there is more surface acting, emotional exhaustion increases. When there is less deep acting, emotional exhaustion decreases. Frequency $(\beta=0.208, \quad p<0.01)$ was found to have impact on depersonalization. In other words, when the frequency of emotional labor increases, depersonalization also increases. Frequency $(\beta=0.305, p<0.001)$ and deep acting $(\beta=-0.157$, $p<0.01)$ were found to have impact on reduced personal accomplishment. In short, when the frequency of emotional labor increases, the extent of reduced personal accomplishment increases. When there is more deep acting, the extent of reduced personal accomplishment decreases.

\section{B. The Control Effect of Stress Coping Strategies in the Relation between Emotional Labor and Burnout}

TABLE II: THE CONTROL EFFECT OF STRESS COPING STRATEGIES ON THE EMOTIONAL EXHAUSTION OF EMOTIONAL LABOR AND BURNOUT

\begin{tabular}{|c|c|c|c|c|c|}
\hline & diversity & strength & frequency & surface acting & deep acting \\
\hline *problem-centered area & .057 & .027 & -.032 & -.014 & -.068 \\
\hline *hopeful perspective & -.014 & $.137 *$ & $-.132 * *$ & .004 & .053 \\
\hline *social support search & .052 & -.044 & .035 & -.006 & .019 \\
\hline *positive perspective & .082 & .076 & .023 & -.021 & $.177^{* *}$ \\
\hline$*$ tension relieve & .024 & -.004 & .014 & -.019 & -.111 \\
\hline$R^{2}$ & .330 & 248 & .431 & .386 & .250 \\
\hline$R^{2} \Delta$ & .020 & .026 & .015 & .001 & .031 \\
\hline$F$ & $10.411^{* * *}$ & $6.984 * * *$ & $15.979 * * *$ & $13.262 * * *$ & $7.059 * * *$ \\
\hline$p$ & .000 & .000 & .000 & .000 & .000 \\
\hline
\end{tabular}

TABLE III: THE CONTROL EFFECT OF STRESS COPING STRATEGIES ON THE DEPERSONALIZATION OF EMOTIONAL LABOR AND BURNOUT

\begin{tabular}{|c|c|c|c|c|c|}
\hline & diversity & strength & frequency & surface acting & deep acting \\
\hline *problem-centered area & -.007 & .069 & -.014 & -.023 & -.037 \\
\hline *hopeful perspective & .076 & $168 * *$ & .015 & .084 & .082 \\
\hline *social support search & .075 & .045 & -.004 & .051 & .082 \\
\hline *positive perspective & .119 & .070 & .025 & .079 & .135 \\
\hline *tension relieve & -.096 & .001 & .036 & $-.137 *$ & $-.152 *$ \\
\hline$R^{2}$ & .126 & .125 & .118 & .123 & .109 \\
\hline$R^{2} \Delta$ & .024 & .046 & .003 & .018 & .030 \\
\hline$F$ & $3.055 * * *$ & $3.014 * * *$ & $2.828 * * *$ & $2.955 * * *$ & $2.588^{* *} *$ \\
\hline$P$ & .000 & .000 & .000 & .000 & .001 \\
\hline
\end{tabular}

TABLE IV: THE CONTROL EFFECT OF STRESS COPING STRATEGIES ON THE REDUCED PERSONAL ACCOMPLISHMENT OF EMOTIONAL LABOR AND BURNOUT

\begin{tabular}{|c|c|c|c|c|c|}
\hline & diversity & strength & frequency & surface acting & deep acting \\
\hline *problem-centered area & .006 & .078 & .065 & .079 & .073 \\
\hline *hopeful perspective & .063 & .004 & $128 *$ & .072 & .048 \\
\hline *social support search & -.005 & .008 & .039 & .023 & .043 \\
\hline *positive perspective & -.083 & -.081 & -.033 & -.001 & -.114 \\
\hline *tension relieve & .078 & .034 & .053 & .058 & .090 \\
\hline$R^{2}$ & .207 & 197 & 231 & 213 & .214 \\
\hline$R^{2} \Delta$ & .010 & .009 & .024 & .020 & .020 \\
\hline$F$ & $5.503 * * *$ & $5.189 * * *$ & $6.345 * * *$ & $5.721 * * *$ & $5.763 * * *$ \\
\hline$p$ & .000 & .000 & .000 & .000 & .000 \\
\hline
\end{tabular}




\section{The Control Effect of Social Support of}

Superior/Colleague on the Relation between Emotional

Labor and Burnout

TABLE V: THE CONTROL EFFECT OF SOCIAL SUPPORT OF SUPERIOR/COLLEAGUE ON THE EMOTIONAL EXHAUSTION OF EMOTIONAL LABOR AND BURNOUT

\begin{tabular}{|c|c|c|c|c|c|c|c|c|c|c|}
\hline & diversity & strength & frequency & $\begin{array}{l}\text { surface } \\
\text { acting }\end{array}$ & $\begin{array}{l}\text { deep } \\
\text { acting }\end{array}$ & diversity & strength & frequency & $\begin{array}{l}\text { surface } \\
\text { acting }\end{array}$ & $\begin{array}{l}\text { deep } \\
\text { acting }\end{array}$ \\
\hline & \multicolumn{5}{|l|}{ superiors } & \multicolumn{5}{|l|}{ colleagues } \\
\hline emotional & -.105 & .134 & -.062 & -.086 & .069 & .055 & .084 & .009 & .047 & .125 \\
\hline appraisal & .036 & .058 & .031 & .008 & -.047 & |.056 & .028 & .048 & .019 & -.129 \\
\hline informative & .002 & .064 & .008 & .047 & .018 & |.034 & .023 & -.029 & -.021 & -.018 \\
\hline physical & $204 *$ & $-.144 *$ & .026 & .059 & .108 & -.036 & $-.167 *$ & -.020 & -.032 & .028 \\
\hline$R^{2}$ & .263 & .186 & .401 & .353 & .154 & .296 & .214 & .410 & .373 & .195 \\
\hline$R^{2} \Delta$ & .027 & .024 & .001 & .004 & .020 & $\mid .010$ & .014 & .002 & .001 & .012 \\
\hline$F$ & $8.735^{* * *}$ & $5.609 * * *$ & $16.418 * * *$ & $13.411^{* * *}$ & $4.476 * * *$ & $10.338 * * *$ & $6.663 * * *$ & $17.028 * * *$ & $14.594 * * *$ & $5.951 * * *$ \\
\hline$p$ & .000 & .000 & .000 & .000 & .000 & .000 & .000 & .000 & .000 & .000 \\
\hline
\end{tabular}

TABLE VI: THE CONTROL EFFECT OF SOCIAL SuPPORT OF SUPERIOR/COLLEAGUE ON THE DEPERSONALIZATION OF EMOTIONAL LABOR AND

\begin{tabular}{|c|c|c|c|c|c|c|c|c|c|c|}
\hline \multicolumn{11}{|c|}{ BURNOUT } \\
\hline & diversity & strength & frequency & $\begin{array}{l}\text { surface } \\
\text { acting }\end{array}$ & deep acting & diversity & strength & frequency & $\begin{array}{l}\text { surface } \\
\text { acting }\end{array}$ & deep acting \\
\hline & \multicolumn{5}{|l|}{ superiors } & \multicolumn{5}{|l|}{ colleagues } \\
\hline emotional & .131 & .122 & -.008 & .137 & $.208^{*}$ & .082 & .143 & .027 & $.249 * *$ & $.214 * *$ \\
\hline appraisal & -.150 & -.023 & -.169 & -.148 & -.089 & -.126 & -.061 & -.081 & $-.181^{*}$ & -.113 \\
\hline informative & .126 & .125 & .075 & .041 & .018 & .077 & .000 & .067 & .079 & -.103 \\
\hline physical & .019 & -.063 & .174 & .106 & .024 & .045 & -.059 & .058 & -.070 & .077 \\
\hline$R^{2}$ & .130 & .084 & .143 & .127 & .093 & .115 & .070 & .118 & .135 & .089 \\
\hline$R^{2} \Delta$ & .024 & .025 & .016 & .022 & .033 & .014 & .011 & .009 & .039 & .028 \\
\hline$F$ & $3.675^{*} * *$ & $2.254^{* *}$ & $4.106 * * *$ & $3.580 * * *$ & $2.510 * *$ & $3.200 * * *$ & $1.833^{*}$ & $3.288 * * *$ & $3.844 * * *$ & $2.391 * *$ \\
\hline$p$ & .000 & .008 & .000 & .000 & .003 & .000 & .037 & .000 & .000 & .004 \\
\hline
\end{tabular}

TABLE VII: THE CONTROL EFFECT OF SOCIAL SUPPORT OF SUPERIOR/COLLEAGUE ON THE REDUCED PERSONAL ACCOMPLISHMENT OF EMOTIONAL LABOR

\begin{tabular}{|c|c|c|c|c|c|c|c|c|c|c|}
\hline & diversity & strength & frequency & $\begin{array}{l}\text { surface } \\
\text { acting }\end{array}$ & deep acting & diversity & strength & frequency & $\begin{array}{l}\text { surface } \\
\text { acting }\end{array}$ & deep acting \\
\hline & \multicolumn{5}{|l|}{ superiors } & \multicolumn{5}{|l|}{ colleagues } \\
\hline $\begin{array}{l}\text { emotional } \\
\text { appraisal } \\
\text { informative } \\
\text { physical }\end{array}$ & $\begin{array}{l}.301 * * \\
.032 \\
-.119 \\
-.317 * *\end{array}$ & $\begin{array}{l}.006 \\
.003 \\
-.101 \\
-.076 \\
\end{array}$ & \begin{tabular}{|l|}
-.022 \\
.083 \\
-.136 \\
.122 \\
\end{tabular} & $\begin{array}{l}.034 \\
-.109 \\
.030 \\
.061 \\
\end{array}$ & $\begin{array}{l}.243 * * \\
-.141 \\
-.065 \\
-.023\end{array}$ & $\begin{array}{l}.104 \\
.046 \\
-.030 \\
-.121\end{array}$ & $\begin{array}{l}.040 \\
-.028 \\
-.075 \\
.051 \\
\end{array}$ & $\begin{array}{l}-.034 \\
.004 \\
.045 \\
.099 \\
\end{array}$ & $\begin{array}{l}-.114 \\
.139 \\
.080 \\
.013 \\
\end{array}$ & $\begin{array}{l}-.005 \\
.045 \\
.027 \\
.009\end{array}$ \\
\hline$R^{2}$ & .168 & .115 & .159 & .118 & .128 & .168 & .138 & .188 & .170 & .150 \\
\hline$R^{2} \Delta$ & .058 & .021 & .010 & .004 & .026 & .009 & .004 & .011 & .018 & .004 \\
\hline$F$ & $4.954 * * *$ & $3.177 * * *$ & $4.655^{* * *}$ & $3.293 * * *$ & $3.616^{* * * *}$ & $4.954 * * *$ & $3.943 * * *$ & $5.696^{* * *}$ & $5.021 * * *$ & $4.318 * * *$ \\
\hline$p$ & .000 & .000 & .000 & .000 & .000 & |. .000 & .000 & .000 & .000 & .000 \\
\hline
\end{tabular}

\section{RESULTS}

Main analysis results of this study are as follows.

First, as a result of analyzing the effect of emotional labor on burnout, organizational members with higher academic background had a higher level of emotional exhaustion. And it turned out that as frequency of emotional labor increased and there was more surface acting, the level of emotional exhaustion increased, and as there was more deep acting, the level of emotional exhaustion decreased. As frequency of emotional labor increased, the level of depersonalization increased. As frequency of emotional labor increased, the level of reduced personal accomplishment increased, and as there was more deep acting, the level of reduced personal accomplishment decreased.

Second, for the results of the moderating effects of stress coping strategies, the hopeful perspective area turned out to have moderating effects on strength and emotional exhaustion, frequency and emotional exhaustion, strength and depersonalization, and frequency and reduced personal accomplishment. And it also turned out that the positive perspective area had a moderating effect on deep acting and 
emotional exhaustion, and the tension relieve area had moderating effects on surface acting and depersonalization, and deep acting and depersonalization.

Third, for the results of the moderating effects of social support, physical support turned out to have moderating effects on diversity of emotional expression and emotional exhaustion, and strength and emotional exhaustion. It also turned out that emotional support had moderating effects on deep acting and depersonalization, deep acting and reduced personal accomplishment, and deep acting and depersonalization. And emotional support and physical support turned out to have moderating effects on diversity of emotional expression and reduced personal accomplishment, and surface acting and depersonalization of social supports, it turned out that support of superiors had a larger effect on burnout reduction than support of colleagues.

\section{IMPLICATIONS}

\section{A. Theoretical Implications}

First, existing researches on emotional labor dimensions are mostly based on those of Hochschild and Morris \& Feldman, and most of them mainly dealt with the negative effects of emotional labor. This study, for sub-dimensions of emotional labor, examined the effects of not only surface acting and deep acting but diversity, strength, and frequency on sub-dimensions of burnout, and it was indicated that deep acting of emotional labor decreased emotional exhaustion, which is a positive aspect.

Second, it turned out that as frequency of emotional labor increased and there was more surface acting, the level of emotional exhaustion increased. In his study, Maslach(1982) claimed that burnout progressed through emotional exhaustion, depersonalization, and reduced personal accomplishment, in order. Typical researches also reported that emotional exhaustion was the most fundamental dimension among those that caused burnout of organizational members, resulting in the rest two dimensions. In this study, it was also found that, of the sub-dimensions of burnout, the first stage, emotional exhaustion, was high.

Third, typical researches considered that stress coping strategies played the role of relieving job stress. This study first attempted to consider stress coping strategies as a variable moderating emotional labor and burnout, and it turned out that areas of hopeful perspective, positive perspective, and tension relieve of stress coping strategies influenced elements of burnout.

Fourth, it turned out that physical support and emotional support of social support influenced elements of burnout. Hobfall(1989), using the Model of Conservation of Resources, claimed that resources such as social support relieved burnout. Kirmeyer\&Dougherty(1988) reported that even if employees had the same level of stress, whether they could overcome the stress might vary with strength of social support. This study also confirmed the finding of existing researches that social support played the role of relieving burnout.

\section{B. Actual Implications}

First, it turned out that, on the relationship between emotional labor and burnout, surface acting caused burnout, and deep acting reduced burnout. Like this, results vary with the ways that service industry employees perform emotional labor, and in this study, deep acting of emotional labor reduced emotional exhaustion. Thus, organizations need to grasp the ways that employees perform emotional labor and manage them discriminately, and employees who perform surface acting should try to minimize occurrence of burnout In addition, given the perspective of stages of burnout, because emotional exhaustion influence next stages, depersonalization and reduced personal accomplishment, employees need to properly cope with emotional exhaustion, the first stage of burnout.

Second, because areas of hopeful perspective, tension relieve, and positive perspective of stress coping strategies had moderating effects on elements of burnout, organizations should educate on coping skills focusing on this part, and develop various programs.

Third, for social supports, it turned out that support of superiors had a larger effect on burnout reduction than support of colleagues. Thus, it is needed to seek measures for improving smooth communications and relationships between employees and superiors.

\section{REFERENCES}

[1] A. R. Hochschild, The Managed Heart, Berkeley \& Los Angeles, CA: University of CaliforniaPress, 1983.

[2] B. E. Ashforth and R. H. Humphrey, "Emotional Labor in Service Roles: The Influence of identity," Academy of Management Review, vol. 18 , no. 1, pp. 88-115, 1993.

[3] J. A. Morris and D. C. Feldman, "The dimensions, antecedents, and consequences of emotional labor," Academy of Management Review, vol. 21, 1996.

[4] A. A. Grandey, "Emotion regulation in the workplace: A new way to conceptualize emotional labor," Journal of Occupational and Health Psychology, 2000, vol. 5, no. 1, pp. 95-110

[5] C. B. Maslach, "A Multi dimensional Perspective," in Professional Burnout: Recent Developments in Theory and Research, W. B. Schaufeli, C. Maslach, and T. Mark (Eds), Washington, DC: Taylor \& Francis, 1993.

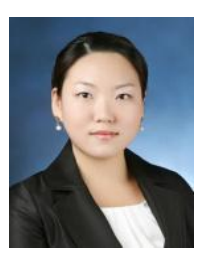

Yeong Gyeong Choi was born on July 10, 1985 in Daegu, South Korea. Currently, She is Ph.D. candidate in Kyungpook National University. Her areas of interest include emotional labor, emotional intelligence, leadership, organizational citizenship behavior. She has participated in many researches. She is actively involved in teaching, research and publication. 